\title{
The Impact of Good Quality Instructions of Early Education on the Performance of University Newcomers
}

\author{
F. H. AL-Othman ${ }^{1}$ \\ ${ }^{1}$ The Public Authority for Applied Education and Training (PAAET), Kuwait \\ Correspondence: F. H. AL-Othman, The Public Authority for Applied Education and Training (PAAET), Kuwait. \\ E-mail: fadel_osman@hotmail.com
}

Received: November 20, 2013

Accepted: February 10, 2014

Online Published: February 19, 2014

doi:10.5539/jel.v3n1p 111

URL: http://dx.doi.org/10.5539/jel.v3n1p111

\begin{abstract}
Good quality instruction in the early years of education has a positive impact in helping newcomers in universities and colleges to adapt to the new environment. This concept is widely applied in contemporary higher education because of the numerous benefits it offers to the students and the instructors. It, is not therefore, subject to the context from which the writer comes from but it is considered a global issue which requires rigorous investigation from researchers and educators from different academic backgrounds on the grounds that newcomers in institutions of higher education are faced with numerous challenges that render them incapable of adapting, and performing well in their first days. Intensification of good quality instruction is inevitable for students to perform well in such an academic climate. Therefore, this article focuses on numerous components of good quality instruction, interventions made by university tutors, and the negative effects of lack of good quality instruction on the educational process of learners at a later stage. Moreover, the paper focuses on the importance of quality education to newcomers in preparation for higher levels of educations in order to be prepared for life challenges after graduation. It also attempts to describe the nature in which contemporary higher learning has evolved to necessitate adoption of good quality instruction in the curriculum.
\end{abstract}

Keywords: good quality instruction, cognitive development, university freshmen, curriculum, instructional evaluations

\section{Introduction}

After almost nine years of teaching experience in the English Language Department at the College of Basic Education in Kuwait during which my colleagues and I as well as other staff members from different departments, came to a conclusion that our students' level of performance leaves much to be desired not only in the English language but in other disciplines as well. Confessions from colleagues in other departments together with my observations during my Translation classes unveiled this problem which could be attributed to lack of good quality instructions of the students' earlier educational phase. Therefore, the writer thought of probing into this important educational constituent in order to see whether there is a link between good quality instruction of students' earlier education and that of current students' performance in the colleges and universities in general.

The endorsement of good quality instruction during early education has been proved to be of a major importance, especially for newcomers in higher educational institutions for the reason that new students are faced with challenges that render them incapable of adapting well enough to the university climate; therefore, it is paramount to incorporate such a concept for the benefit of the students and the institution at large, particularly if we take into account that contemporary learning institutions have increased in the last decade or so. Moreover, learning time has been reduced and hence little time is dedicated to helping new students cope with the new environments. The impact of quality education on the life of the students in a later academic phase cannot be overemphasized. Students are the most important resource in a nation and should be given relevant instruction to facilitate the achievement of relevant skills.

Good quality instruction for early education is essential for the success of the students, especially those from disadvantaged background. Governments all over the world continue to see the importance of good quality education and have instituted programs to ensure that there is good quality instruction during early education. In the United States' programs, for example, the government's policy is to ensure that students get the quality education that they deserve. Such programs have proven beneficial for the students and even the society at large 
with some having a return of up to $18 \%$ of the investment. Another advantage for this, is the increased income of the students when they secure employment.

Augmentation of quality instruction is pivotal to students' performance when facing a different life away from home. The discernment of learners in institutions of higher education concerning major factors of high quality instruction will be discussed in this paper. Students' perception of instruction from female teachers, administrative teachers, performance in common or social units is usually high in view of fresh students in colleges and universities. High-quality instruction process enhances teachers' creativity to produce meaningful methods of learning such as teacher-student interaction, preparation, curriculum design, instructional activities and monitoring among others to enhance the social life of new students at school.

Good quality instruction is based on the intentions of students joining the university, their efforts, social support and backing. It can be realized through the factors of higher education and education in general such as curriculum design, administrative support, selection of teaching materials, teacher's traits, equipment, student-teacher interactions among others. This goes in conjunction with positive interaction, learning opportunities motivation and so on.

Furthermore, such educational criteria indicate a school's quality in service and ability to meet the demands and needs of new students. Areas of improvement in the instructional process and outcomes in terms of the student's performance could be discovered by evaluation of the instructional process. Teachers could enhance a student's interest in learning and their explanations and demonstrations during their stay in university, and more specifically, trigger the student's learning interests.

Moreover, it is necessary in the development of an avalanche of skills during early education. Such a form of instruction is vital because most of the newcomers in the universities lack the experience and qualifications that enable them to adapt effectively in their new environment. Good quality instruction curriculum is necessary to help new students cope with the challenges prevalent during the first days. In a university scenario, students in advanced classes have a greater level of independence and voice their opinions in a more confident manner than the newcomers.

The study on the impact of good quality instructions entails a focus on the impact of such instructions on the performance of particular students on certain skills. These include integrated writing, discussion, and writing activities. Simply, new students learn more when they write and discuss what they have learned (Abrams, Pedulla \& Madaus, 2003).

\subsection{Research Method}

The In this research an inductive approach is used to develop a correlation between good quality instructions at childhood and the academic performance of children in their higher education. The research relied primarily on secondary data in additionto primary data collected by the investigator. The findings from the secondary sources were linked to those from the primary sources. In other words, the research is of a theoretical nature. It was guided by the following research questions.

\subsection{Research Question}

1) What is good quality early education?

2) Is there a correlation between university students' academic performance and early education?

3) Does early education have an influence on the performance of the students in their first years in college?

\subsection{Research Significance}

It is hoped that the research will alert educators in the college of Basic Education, the Ministry of education in Kuwait, and researchers worldwide of the importance of early good quality instructions on the performance of the students in their higher education.

\subsection{Limitations of the Study}

One of the limitations of the research was the likelihood of the researcher's bias in the study because the investigator was inclined toward validating the hypothesis that offering good quality early education to children has a positive impact on their academic performance later in life. This was, however, cancelled out by the reliance of the study to a vast amount of secondary sources. The writer's analysis will present the study with enhanced internal validity. 


\section{Literature Review}

According to Shonkoff et al. (2007), the development of a child can be divided into five domains, each having far reaching effects on the life of the child in later life. These five developmental domains include: cognitive, physical, emotional, social, and language development skills. Cognitive development can be divided into four stages according to age. Between birth and 2 years of age, learning of the child is based primarily on physical interaction and experiences, a stage known as sensorimotor stage. Piaget (2008) emphasizes that from the age of 2 years to about 7 years, there is an increased demonstration of intelligence through the use of symbols, imagination and memory. There is also a better use of language; thinking is however non-logical, non-reversible and egocentric. At the third stage of cognitive development which is between 7 and 12 years mostly the thinking improves, becoming logical and systematic. The final stage is the formal operational stage which occurs from the age of 12 to beyond. At this stage thinking becomes more abstract and hypothetical. Key to the success and life fulfillment of an individual is the early years of life.

Ginsburg (2007) indicates that neurological development depends on the exposure to educational material through the means of visual, audio and sensory, all functioning cognitively to the surrounding environment. The extent to which this learning development occurs, limits the extent to which an individual can learn in later life. At the university level, this may reflect in a number of ways. The learning at this stage may contribute to early education as it sets the capacity of the brain in the ability to recognize patterns and memory which are important in the learning process at later life. The age of 2 years to 7 years is the age when the learning process is most active and contributes to later learning at the university level. The appropriate stimulations lead to creation of neutral pathways that enhance the social, emotional, and thinking abilities, all through to adulthood. The phase of study at the university level occurs and is limited from the very beginning by the number of neural pathways created, states

With an increasing number of women joining the workforce, the number of children being cared for by someone other than their parent is on the increase. Scientists have studied the effects of such a phenomenon on the ability of children to learn. The children in a single parent setting are even more at risk of suffering from low count of neutral connections because of exposure to dull and mostly unresponsive environment (Meyers \& Jordan, 2006). The curiosity and playful nature of children are means to good quality instruction for early education. For beginners of the university level the impact of this is reflected through the performance in subjects requiring certain skills that were acquired during the important 2-7 years phase of development. The courses are then classified into levels depending on the quality and type of skills required. The students in choosing their majors in the university gauge their ability in these skills against such requirements. Liu (2010) points out that students who were exposed to good quality instruction for early education, rate higher than the others in all the subjects as they are well rounded. Through the exposure to activities that develop the skills which is required by each subject, the students are better positioned.

Simpson, LaCava, \& Sampson (2004) indicate that exposure to positive and stimulating activities at early stage of development enhance the learning capabilities of students. Such students have higher than average IQs. Coined from the German word Intelligenz-Quotient, IQ is the measure of the intelligence. A score in IQ has been shown to relate to the educational capabilities principally at the university level. The IQ test is designed in such a way that shows the majority of the population around $95 \%$ is average. Usually a score of $70-130$ is adopted as a yardstick for measuring the level of intelligence i.e. anyone who scores above 130 is of superior intelligence and anyone who scores below 70 is below average. Research has found out that a correlation exists between the learning that occur during the critical stages of child development and the level of IQ. Those exposed to good quality education for an early education tend to score high than those that have a different experience at the early stage of development (Ramey \& Ramey, 2004).

Fitzpatrick, Sanders and Worthen (2004) emphasize that the results of good quality instruction at an early stage improve the capacity of the student, thus easily adapting him/her to the requirements in order to be a better performer. The students that have had good quality instructions for their early education are more ready to learn when they join the university. This may be as a result of their ability to perform well in the past and their gained knowledge makes them more able to handle the future challenges. This may stem from the good quality instruction that employ a reward system for those who perform and allow for the child to learn at their own pace.

Bullough, Clark and Patterson (2003) concur indicating that the purpose is to enable the child to associate a positive feeling to the learning processes; therefore, he is ready and more willing to learn later in life, especially at the university level where learning is greatly self- motivated. Good quality instruction for an earlier level facilitates the continued motivation of students to pursue education to high levels such as the university and even 
further. The beginning of learning at the university can be very challenging for students. The advantage of having the skills acquired through the early education system can prove invaluable in tackling the hindrances that arise at this level of schooling.

There are numerous definitions of good instruction which are in the form of instructional components inevitable for achievement of high literacy levels. Coherence of the instructions is among the components necessary for good quality instructions. This is a reference to the extent to which discussion, writing, and reading activities are merged to aid the learning process. Another element with this regard is the students' voice. Engagement of students in the learning process helps in constructing their learning experiences and build self-confidence. This element is supported in good quality instruction. Content emphasis is another element in good quality instruction (Temple \& Reynolds, 2007).

The journal Early Childhood Education for all: A Wise Investment (2005) asserts that student's items of satisfaction in class depend on the attitude to serious instruction, positive teacher-student interaction, and rich instructional content. Student's views on their teacher's level of quality instruction shows varying reactions. Teachers are different concerning serious instruction attitude, teacher-student closeness, teaching flexibility, adequate assignments, multiple evaluations, teacher's proper conduct, and use of instructional resources. There is an argument that teachers are important factors in enforcing students' attitudes and motivation. In this vein, Mallalah (2004) in his study draws a contrast between native English speaking EFL teachers and non-native speaking teachers. The findings indicate that Kuwaiti high school students had strong favorable attitudes towards the former. They were viewed by their students as honest, hard-working, efficient, kind intelligent, cheerful, well-mannered, polite and humorous. In other words, they were close to the hearts and minds of the students than their non-native counterparts.

Kleinhenz and Ingvarson (2004) reveals that new students are usually more responsive to female teachers than male teachers. This indicates that female instructions are generally more accepted by students. Males and females are considerably unlike. Male teachers tend to catch the attention of students through their funniness; female teachers habitually care for students, and they are affectionate and watchful; thus, gender will influence the critical results. Coherence of the instructions is among the components necessary for good quality instructions. However, male and female characteristics can be shown in instructions to condense the differences in logical results.

Ballard and Bates (2008) indicate that the discussion of the impacts of good quality instruction could also be based on the teacher holding, either fulltime, or part-time posts. The expectations of the student are greater from fulltime than part-time teachers. Students have shown more satisfaction to fulltime and administrative teachers than with part-time teachers. They also add that the performance of students in units facilitated by full-time and administrative teachers is remarkably better than the students' counterparts and this may be linked to the teachers' extensive experience in the fields they teach. Students are more satisfied with quality instructions from these experienced teachers. Because of their experience, they can clearly figure out the learning demands of each student and help them with various learning issues through instructional and administrative resources.

Cankoy\& Tut (2005) indicate that students in many colleges major in different subjects and the college standard differences could alter the results of evaluation of the instructional process. Scores in subjects' evaluation may be lower in science related courses and relatively lower in non-science related courses. Most colleges are more satisfied with proposals from teachers on effectual learning strategies and instruction; some are based on teacher's instruction.

Forecast of a student's active education is more vital to academic accomplishment than submissive learning. Students in their later years are more satisfied and more performing in elective courses than compulsory courses. They are more satisfied with elective courses with regard to recognition of student's capability and good coordination of schedule but are less satisfied with obligatory courses. This is because elective courses are more instructional and provide them with more freedom of choice than obligatory courses. Students are then more contented with instruction in elective courses, as their best score, followed by general knowledge course and lastly obligatory courses. Students mostly perceive obligatory courses as a forced phenomenon and therefore may not evaluate the teachers of such subjects highly. There are impacts of instructional goals on a serial curriculum in the obligatory courses because they are somehow more engaging (Chipman, Segal, \& Glaser, 2013).

A look at the components for good quality instruction reveals the attributes mentioned in the literature review. Giving the university newcomers a lot of homework has a positive ramification in the realm of quantity. Concisely, this aspect helps them to read more and this in turn is translated to a high retention factor. Measures 
adopted during good quality instruction are intended to facilitate coherence of the students' instruction and content which have a significant effect in helping newcomers to discuss readings, assignments, and report writing. With regard to the students' voice, activities during the implementation of good quality instruction, designed to help them gain understanding, had a significant effect on their performance. Similarly, the choice of the students in readings manifested in oral reports and discussions led by the students had the effect of improving the performance of university newcomers (Gallagher, 2002)

With regard to the category of content emphasis, timely implementation of good quality instruction enhanced achievements in reading. Focus on analytic and literal study had an important effect in ameliorating the performance of the university newcomers. Generally, the bottom line of the study on the impact of good quality instruction revealed that by engaging university newcomers in various approaches to content such as literature study, analytic writing and intensive activities designed to enable students demonstrate how well they understand the material, had a positive influence on the achievements made in reading, extracurricular, and social activities. Moreover, good quality instruction and content helped the university newcomers because it mitigated the effect of economic and social status on the reading achievements of the university newcomers. The most affected individuals by the findings of this study were university newcomers and the teachers vested with implementing good quality instruction (Linn, 2003).

The aforementioned study was based on the data reported by the university newcomers and the authorities who assessed them. In light of this, participants interpreted a variety of questions and terms that tended to affect their responses. Concisely, the actual practice of giving good quality instruction to university newcomers may differ from the findings in this study. In the research on the various components of good quality instruction, the study revealed the important nature of these instructional components and literary strategies had a positive effect on reading achievements and also produced significant results in domains such as writing achievement (Popham, 2004).

Good quality instruction has a variety of attributes. The concept is engaging and differentiated, data driven, based on standards, and based on evidence and research. Assessment, instruction, and curriculum grounded in culturally responsive practices of belonging, identity, community, and relevance should be appropriate with regard to culture. This is because it prepares new students, university newcomers in this case, with relevant approaches to the multicultural world. Furthermore, good quality instruction for early education has an impact on the inclinations to crime and antisocial behavior. Students that experience positive and engaging environments during an early stage of development are less likely to involve themselves in criminal activity even at the university level. The changed social setting at the university and the monetary freedom that follows can pose a challenge to students. The ability of the students to tackle this is enhanced by positive early education. Good quality instructions for early education facilitate students finding better ways to interact with others (Popham, 2005)

Research has shown that adjustment to a new environment can affect the performance of students. The university beginners are exposed to a different environment. This adjustment stress manifests its self in the first semester of learning as having low grades. Good quality instruction for early education increases a student's ability to adapt and perform in a different environment. Students that have experienced positive early education will attune better at the university and are more likely to perform better in the exams. These students are also less likely to fail to reach the cutoff point thus rarely repeat levels in the university (Sweeney, 2000).

Due to the high cutoff point usually set by the educational bodies, the access to higher education and especially at the university level is limited to those who have an ability to learn better. Better learning is greatly dependent on the ability to remember and find patterns in data. Good quality instruction for early education enables the development of these capabilities. Students that have been instructed better on the critical development stage of early education have the ability to remember the information given to them at this early stage and beyond. They perform better at the high school and college level and comprise the majority of those that join the university (Sweeney, 2000).

According to Vandevoort, Amrein-Beardsley and Berliner (2004) graduate students are more satisfied with the teacher's high-quality instruction than are the newcomers. Thus, graduate students who are exposed to good instructional techniques in their earlier years seem to uphold teacher's instruction more effectively at a later stage. New students in universities are 18 years on average, and young people are usually emotional. Graduate students are much older and are therefore more calm and rational. Most university newcomers are almost unsure of the careers they want to pursue and their learning is usually influenced by colleagues, interests, hence, their learning is mostly inactive could be overwhelmed by the future uncertainty. 
Graduate students are more active and approach teachers with academic problems unlike the university freshmen. The formers learning inspiration tends to be influenced by their positive evaluation of their teachers' high quality instruction. Key to the success and life fulfillment of an individual is the early years of life. Neurological development depends on the exposure to educational material through the means of visual, audio and sensory, all functioning cognitively to the surrounding environment. The extent to which this learning development occurs limits the extent to which an individual can learn in later life. At the university level this may reflect in a number of ways. The learning at this stage is a possible contribution to early education as it sets the capacity of the brain in the ability to recognize patterns and memory which are key in the learning process at later life (Fei, 2008).

In assertion of the above, in a study conducted in the four colleges of the Public Authority for Applied Education and Training (PAAET) in Kuwait, the findings show that \%80 of the respondents attributed their low performance in English language to problems with learning the language at an earlier stage (AL Othman, 1996). This could be an indication that students were not well prepared in their earlier schooling to face the current challenges and demands of their undergraduate studies (Whetton, Ruddock \& Twist, 2007). Moreover, the Assistant Undersecretary for Information and Planning at the Ministry of Education confirmed that a number of distinguished secondary school graduates, who were in scholarships, are unable to pass the aptitude tests in universities abroad i.e. in the West (Al-Watan Newspaper, 2013). This is another indication that good early education has serious consequences on the progress of the students in their future studies.

Commitment to high quality training should cause a school or a region to evaluate its move toward interventions. Before interventions, for undersized groups or entity, there should be information from multiple sources that indicate a high quality instruction is occurring for most of the students at a universal level. Moreover, curricular adjustments are supposed to be made before considering additional sustenance (Houston, Meyer, \& Paewai, 2006)

Also, research findings from University of Chicago and the University of North California at Chapel Hill (2013) show a strong correlation between good quality instruction provided for children and to later ability on tests of understanding analogies. These students are also less likely to fail to reach the cutoff point thus rarely repeat levels in the university. Once high dominance instruction is recognized at the global level, supplementary hold from the classroom tutor and professionals should be offered as an intercession choice before thinking about a unique teaching proposal. Referrals to certain forms of education should be considered when authorized data elucidates that a student is not responding to some instructions. This should also happen when the student fails to make progress to high quality instruction and technical interventions (Houston, Meyer, \& Paewai, 2006).

Educators ought to be considerate in assuring that student accomplishes a large amount of tasks. The data they collect from students should prove that the instruction is of high quality and matches student requirements. Furthermore, there exists the need to gather data which reveal that a section of the students does well after good quality instruction. This could mean examining data in a variety of ways (Chien, 2007)

On the students' perspective, high quality instruction satisfies them with regards to serious instructional attitude, and they view that teachers' stimulation of learning interests should be enhanced. High quality instruction entails positive student-teacher interactions, rich instructional content, and respect for student's responses, reliability, apparent demonstrations and explanations, and teacher's application for instructional strategies. Most students are for the thought that their teachers require incentive to learning interests. Teachers need to improve on flexible teaching, respect for their students, explaining and demonstrating skills, recognition of the student's intelligence quotient, and adequate assignments beyond practicing high quality instructions on the student upon joining the institution (Emanuel \& Adams, 2006).

\subsection{Answers to the Research Questions}

As above noted, good quality education is branded by certain qualities which answers the first research question, whereas the answer to the second questions becomes conspicuously positive by showing a strong correlation between a good quality instruction of early education and the performance of university newcomers. This impact could be rendered to one or more of the factors discussed in the literature, most of which are genetic, psychological, neurological, social, economic, administrative, cultural, political, and cognitive among other factors. To answer the third research question, the earlier discussion shows that there is a strong correlation between the performance of the students in their first year of college and that of the early education.

\section{Recommendations}

The changing social setting and the increased need for additional income in most cases drive children to child care and pre-school centers where they are cared for. In this case, children need trainers qualified for the task. 
There is also a high rate of single parents with countries like America having a rate of $25 \%$. Education policy makers should focus on this stratum and seek better methods of ensuring good quality instruction for early schools. The advantages of this: better performance and high levels of learning, higher adaptability to changing environment and an increased number of students qualifying for education at the university. High quality instruction requires multiple evaluations in order to improve instructional issues. The aims must be varied, according to immediate requirements of students (Richardson, 2005).

In instructional evaluations, specialized fields vary in schools and departments within the university. In addition, information arrangements and instructional goals are diverse. Hence, the assessment content and manner should be according to these different attributes to achieve true instructional valuation. Gender comes with different characteristics. Teachers exhibit personal characteristics during the course and provide a variety of directions. The influence of lecturers is limited in class. However, teachers can foster the endeavors in the aforementioned realm via workshops of good quality instruction or through enquiring from a professional teacher, community and institute which represent rewarding scheme for established teachers. University tutors are more inspired to attend on how to improve instructional methods and quality. Teachers with diverse tenure can share their instructional skills as a way of exchanging experiences (Richardson, 2005).

For newcomers in the university to achieve high levels of performance in all domains, there exists the need to equip them with the necessary skills in academic, social and cultural realms. These are contained in high quality and culturally responsive behavioral and academic instruction. These instructions should be differentiated for all students because of disparities in cognitive abilities (Murray \& Howat, 2002).

The rationale of good quality instruction has to take into account the preparation of newcomers in universities with better adaptive approaches. This feat is achieved through balanced assessment and collaborations that reflect practices, which are culturally responsive. In good quality instruction, collaboration and balanced assessment interact to ensure that all students receive the relevant knowledge and insight for higher behavioral and academic performance. Such collaboration and balanced assessment are powerful when braided or organized to assume systemic functions for all students. The focus of good quality instruction is therefore, to approach student teaching comprehensively (Hung \& Yang, 2009).

The vision for student's success is globally benchmarked by rigorous academic standards cater for the content of good quality instruction and curriculum. Moreover, such academic standards should be implemented for a balanced system for assessment that supports the aforementioned standards. Also, the adoption of all measures provided for good quality instruction prepares university newcomers for higher levels of learning, work and a meaningful life. Publications on good quality instruction provide students with a successful vision, guiding principles for learning and teaching. Moreover, they locate the ideal standards within a support system where collaboration, balanced assessment and relevant instruction function together to facilitate student learning (Richardson, 2005).

Commitment to good quality instruction drives a particular university or college to evaluate interventions' approach. Prior to making interventions for an individual or a group of students, there is the use of data from various sources, which reveals how the instructions are affecting the students at a universal level. For example, the process may review data on the performance of the students. This data may reveal that certain students are not meeting some targets. Relevant adjustments concerning the curriculum should be made for additional support to facilitate learning and behavioral achievement (Richardson, 2005).

Once the good quality instruction has been established at a universal level, support from specialists and the teachers should be embraced as supplementary intervention before considering referrals. Referrals should be made only when data demonstrates that students are not responding to or making progress to interventions and instructions. Educators have to be vigilant to ensure that the collected data on students' achievement proves that instructions and interventions are of high quality and match the needs of the students. There is also the need to gather data revealing that most of the students are doing well after interventions and instructions (Linn, 2003).

\section{Conclusion}

It is hoped that the factors influencing good quality instruction of early education already discussed will give insight for potential researchers to carry out their own research in this area in more depth. It is also expected that the attention of educators as well as policy makers is drawn to take into account the importance of providing good quality instruction for young learners in order to make sure that they will be better performers in a later stage of their education. Good quality education focuses on providing students with long-term ability to achieve good grades (Magnuson, Ruhm, \& Waldfogel, 2007). It is designed to push a student to achieve their academic 
dreams. The quality of education in the early stages of learning depends on the competence level of the teachers. This includes their teaching abilities and their knowledge level (Urban et al., 2012). As revealed by the reviewed literature, there is a strong relationship between the performance of students in universities and colleges and their access to good quality instructions in their early development stages (Burger, 2010). The presence of quality education in the early stages of learning enhances the performance of students in their higher education. The relevant authorities need to recognize this phenomenon and make the required investments in early childhood education. Research also indicates that the relationship formed between the instructors and children in the early learning stages is influential on the cognitive development of children. This is translated in their academic performance in the higher education level (Rentzou \& Sakellarious, 2011).

Good quality instruction for early education has been in an upward trend in many parts of the world. Survey shows that the national percentage of children between the ages of 4 years and 5 years getting a quality education is $52 \%$ though an improvement of the quality of the education varies greatly depending on the status of the area. Poor quality education mostly occurs in low income areas, where the rate of enrolment is ground-level. It reaches as low as $24 \%$ in some areas. Most children are then not receiving the good quality instruction necessary for the improved growth, for future achievement in the educational institutions and for the practical life in general. Good quality instruction has demonstrated an increased rate of growth for children allowing improved development of the brain thus more neural pathways. The result is an individual with high IQ, improved learning and adaptability. There is also the improvement of the cognitive abilities, key in the general life development of an individual.

The emphasis on this stage of learning cannot be overlooked simply because the learning experience in this stage of development has a direct impact on the ability of the child to learn later in life. Stalling performance as a result of a poor quality instruction, occurs in the low income areas at higher rates. Good quality instruction for early education is key to improving the ability of the future generation of the national population to achieve higher levels of performance key in the development of the living standards of the population as a whole and the nation at large. The development of the child is simply the most limiting fact in the achievement of an individual in educational circles. The early stages of development should be given more importance as studies show that there is a correlation between the development of the brain and the cognitive abilities. The behavior of the group achieving the points required to go to universities is for those experiencing the benefits of a good quality education. A comparison between the rate of enrollment and completion with the percentage of those who got good quality instruction during the important stage of early development shoes that there is a significant relationship.

Good quality instruction curriculum is essential to help new students to cope with the challenges prevalent during the first days in the university environment; students in advanced classes have a greater level of self-determination and voice their opinions more confidently than the newcomers. Good quality instruction can be realized through the factors of higher learning and education such as curriculum design, administrative support, selection of teaching materials, teacher's traits, equipment, student-teacher interactions among others. This goes in conjunction with positive interaction, learning opportunities etc.

Offering good quality instruction is necessary to interventions for newcomers in higher learning institutions. With the advent of globalization, there has been arisen scenario whereby many institutions of higher learning potentials have emerged. Moreover, the duration for learning has also been reduced. These developments necessitate the need for good quality instructions to enable newcomers in such institutions to cope and settle down as soon as possible. Good quality instruction crops up to solve problems faced by new entrants to high schools and universities. Starting from early education to high school, the impact of good quality instruction is apparent because it facilitates achievement of cognitive and behavioral attributes vital in dealing with real life situations.

Good quality instruction for early education is essential for the success of the students especially those from a disadvantaged background. Governments all over the world continue to see the importance of this issue and have instituted programs to ensure that there is good quality instruction during early education. In the United States programs such as head start ensure that students get the quality education that they deserve. Such programs have proven beneficial for the students and even the society at large with some having a return of up to $18 \%$ of the investment which could have a positive impact on students' job prospects when they become adults.

Enhancement of quality instruction is key to students' performance when facing a different life away from home. Good quality instruction process enhances teachers strengthening meaningful methods of learning such as 
teacher-student interaction, preparation, curriculum design, and instructional activities and monitoring among others to enhance the social life of new students at school.

Good earlier education is based on the intentions of students joining the university, their efforts, social support and backing. High quality education can be realized through the constituents of higher learning and education such as curriculum design, administrative support, selection of teaching materials, teacher's traits, equipment, student-teacher interactions, positive interaction, learning opportunities and so on. Good quality instruction indicates a school's quality in service and ability to meet the needs and demands of new students. Areas of improvement in the instructional process and outcomes in terms of student's performance could be discovered by evaluation of the instructional process. Teachers could enhance a student's interest in learning and their explanations and demonstrations during their stay in the university or college, and more specifically, trigger the student's learning interests.

To sum-up, good quality instruction is necessary in the development of an avalanche of skills during early education. Such form of instruction is vital because most of the newcomers in these educational institutions have a lack of experience and qualifications that enable them to cope effectively in their new environment. Good quality instruction curriculum is necessary to help new students to face the challenges prevalent during the first days. In the university scenario, students in advanced classes have a greater level of independence and voice their opinions in a more confident manner than the newcomers. The study on the impact of good quality instruction entails a focus on the effect of instructions on the performance of particular students which include integrated writing, discussion, and writing activities. In other words, new students learn more when they write and discuss what they have learned. It is therefore little wonder that our students in the College of Basic Education struggle to survive the challenge in order to meet the demands they are faced with by their disciplines simply because they have not been well prepared in their earlier education.

\section{References}

Abrams, L. M., Pedulla, J. J., \& Madaus, G. F. (2003). Views from the classroom: Teachers' opinions of statewide testing programs. Theory into Practice, 42(1), 19-29. http://dx.doi.org/10.1207/s15430421tip4201_4

Al Othman, F. H. (1996). ESP students' underachievement, possible reasons and solutions with special reference to the Public Authority for Applied Education and Training PAAET) in Kuwait. (Unpublished Phd thesis). University of Bath, UK.

Al Watan Newspaper. (2013, May). Thu 23, May 2013. No: 13447-2893-year 5.

Ballard, K., \& Bates, A. (2008). Making a connection between student achievement, teacher accountability and quality classroom instruction. The Qualitative Report, 13(4), 560-580.

Bullough, R. V., Jr., Clark, D. C., \& Patterson, R. S. (2003). Getting in step: Accountability, accreditation, and the standardization of teacher education in the United States. Journal of Education for Teaching, 29(1), 35-51. http://dx.doi.org/10.1080/0260747022000057945

Burger, K. (2010). How does early childhood care and education affect cognitive development? An international review of the effects of early interventions for children from different social backgrounds. Early childhood research quarterly, 25(2), 140-165. http://dx.doi.org/10.1016/j.ecresq.2009.11.001

Cankoy, O., \& Tut, M. A. (2005). High-Stakes testing and mathematics performance of fourth graders in North $\begin{array}{llll}\text { Cyprus. The Journal of Educational Research, 98(4), 234-243. } & \text { The }\end{array}$ http://dx.doi.org/10.3200/JOER.98.4.234-244

Chien, H. C. (2007). Interpretation and inspiration of high-quality instruction. J. of Educational Research and Development, 2(2), 1-17.

Chipman, S. F., Segal, J. W., \& Glaser, R. (Eds.). (2013). Thinking and Learning Skills: Volume 2: Research and Open Questions. London: Routledge.

Legal Momentum. (2005). Early Childhood Education for all: A wise Investment - a report on the economic impact of child care and early education. NY, 243.

Emanuel, R., \& Adams, J. N. (2006). Assessing college student perceptions of instructor customer service via the Quality of Instructor Service to Students (QISS) Questionnaire. Assessment \& Evaluation in Higher Education, 31(5), 535-549. http://dx.doi.org/10.1080/02602930600679548 
Fei, T. N. (2008). Study on evaluation standard of class instruction from modern instructional view. J. of Educational Research and Development, 4(2), 1-17.

Fitzpatrick, J. L., Sanders, J. R., \& Worthen, B. R. (2004). Program Evaluation: Alternative Approaches and Practical Guidelines (3rd ed., pp. 86-148). Boston: Pearson Education Inc.

Gallagher, H. A. (2002). The relationship between measures of teacher quality and student achievement: The case of Vaughn Elementary. Paper presented at the annual meeting of the American Educational Association, New Orleans, LA.

Ginsburg, K. R. (2007). The Importance of Play in Promoting Healthy Child Development and Maintaining Strong Parent-Child Bonds. American Academy of Pediatrics, Clinical Report, January 2007.

Houston, D., Meyer, L. H., \& Paewai, S. (2008). Academic staff workloads, and job satisfaction: Expectations and values in academe. J. of Higher Educ. Policy and Management, 28(1), 17-30. http://dx.doi.org/10.1080/13600800500283734

Hung, C. H., \& Yang, C. L. (2009). Study on Factors of University Students' Evaluation on Teachers' Instructional Outcomes - Using One Private University in Taoyuan County as an Example. Retrieved from http://www.cycu.edu.tw/ edu/download/07.pdf

Kleinhenz, E., \& Ingvarson, L. (2004). Teacher accountability in Australia: Current policies and practices and their relation to the improvement of teaching and learning. Research Papers in Education, 19(1), 31-49. http://dx.doi.org/10.1080/0267152032000176963

Linn, R. L. (2003). Accountability: Responsibility and reasonable expectations. Paper presented at Presidential Address of the American Educational Research Association. Chicago.

Liu, R. L. (2010). How do university students learn successfully? Review on enhancement of educational quality upon university students' satisfaction with learning outcomes and schools.

Magnuson, K. A., Ruhm, C., \& Waldfogel, J. (2007). Does prekindergarten improve school preparation and $\begin{array}{lllll}\text { performance? } \quad \text { Economics } & \text { of }\end{array}$ $\mathrm{http}: / / \mathrm{dx}$. doi.org/10.1016/j.econedurev.2005.09.008

Malallah, S. (2000). English in an Arabic Environment: Current Attitudes to English among Kuwait University Students. Int. J. Bilingual Educ. Bilingualism, 3(1), 19-43. http://dx.doi.org/10.1080/13670050008667698

Meyers, M. K., \& Jordan, L. P. (2006). Choice and accommodation in parental child care decisions. Community Development, 37(2), 53-70. http://dx.doi.org/10.1080/15575330609490207

Murray, D., \& Howat, G. (2002). The relationships among service quality, value, satisfaction, and future intentions of customers at an Australian sports and leisure centre. Sport Management Review, 5(1), 25-43. http://dx.doi.org/10.1016/S1441-3523(02)70060-0

Piaget, J. (2008). Encyclopedia Britannica. Encyclopedia Britannica Online.

Popham, W. J. (2004). Curriculum, instruction, and assessment: Amiable allies or phony friends? Teachers College Record, 106(3), 417-428. http://dx.doi.org/10.1111/j.1467-9620.2004.00345.x

Popham, W. J. (2005). Classroom assessment: What teachers need to know (4th ed.). Boston: Pearson, Allyn, and Bacon.

Ramey, C. T., \& Ramey, S. L. (2004). Early learning and school readiness: Can early intervention make a difference? Merrill-Palmer Quarterly, 50(4), 471-491. http://dx.doi.org/10.1353/mpq.2004.0034

Rentzou, K., \& Sakellarious. (2011). The Quality of Early Childhood Educators: Children's Interaction in Greek Child Care Centers. Early Childhood Educ J, 38, 367-376. http://dx.doi.org/10.1007/s10643-010-0403-3

Richard, L. E., \& Burchinal, M. R. (2013). Early Executive Function Predicts Reasoning Development. Psychological Science, 24, 87-92. http://dx.doi.org/10.1177/0956797612450883

Richardson, J. T. E. (2005). Instruments for obtaining student feedback: A review of the literature. Assessment \& Evaluation in Higher Educ., 30(4), 387-415. http://dx.doi.org/10.1080/02602930500099193

Shonkoff, J. P. et al. (2007). The Science of Early Childhood Development: Closing the Gap Between What We Know and What We Do. National Scientific Council, Center on the Developing Child, Harvard University. 
Simpson, R. L., LaCava, P. G., \& Sampson, G. P. (2004). The no child left behind act: Challenges and implications for educators. Intervention in School and Clinic, 40(2), 67-75. http://dx.doi.org/10.1177/10534512040400020101

Sweeney, J. (2000). Accountability can drive student achievement. Thrust for Educational Leadership, 29(4), 14-19.

Temple, J. A., \& Reynolds, A. J. (2007). Benefits and costs of investments in preschool education: Evidence from the Child-Parent Centers and related programs. Economics of Education Review, 26(1), 126-144. http://dx.doi.org/10.1016/j.econedurev.2005.11.004

Urban, M., Vandenbroeck, M., Van Laere, K., Lazzari, A., \& Peeters, J. (2012). Towards Competent Systems in Early Childhood Education and Care. Implications for Policy and Practice. European Journal of Education, 47(4), 508-528. http://dx.doi.org/10.1111/ejed.12010

Vandevoort, L. G., Amrein-Beardsley, A., \& Berliner, D. C. (2004). Students of nationalboard certified teachers outperform peers on national test. Education Policy Analysis Archives, 12(46).

Whetton, C., Ruddock, G., \& Twist, L. (2007). Standards in English primary education: The international evidence.

\section{Copyrights}

Copyright for this article is retained by the author(s), with first publication rights granted to the journal.

This is an open-access article distributed under the terms and conditions of the Creative Commons Attribution license (http://creativecommons.org/licenses/by/3.0/). 